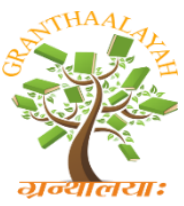

INTERNATIONAL JOURNAL OF RESEARCH GRANTHAALAYAH A knowledge Repository

Social

\title{
THE BASIC SPECIFICITY OF THE ABILITY OF VARIED ENGLISH LANGUAGE CURRICULUMS TO ENHANCE ENGLISH LEARNERS' CAPACITY TO DEVELOP NECESSARY SKILLS TO COMMUNICATE USING THE ENGLISH LANGUAGE
}

\author{
Michael Wayne Hendershot ${ }^{* 1}$, Nutprapha K. Dennis ${ }^{2}$, Suchada Chaiwiwattrakul ${ }^{3}$, Ratirot \\ Phiphitphakdee ${ }^{4}$ \\ *1, 2, 3, 4 English Department, Ubon Ratchathani Rajabhat University, Thailand
}

DOI: https://doi.org/10.29121/granthaalayah.v5.i4.2017.1791

\begin{abstract}
Inasmuch as the goal of teaching English to non-native English speakers should be focused on enhancing English learners' ability to develop skills necessary for efficient and effective use of the English language in communication within their daily lives as well as within the context of educational, employment, governmental, and business related issues, the materials and resources used by the teacher to provide said English learners with enhanced ability to develop necessary skills for the use of the English language for efficient and effective communication are of paramount importance. This study was designed as a comparison of English language curriculums between select schools in an effort to determine the effectiveness of the curriculum to enhance students' abilities to develop skills to be able to effectively and efficiently communicate using the English language. Participants in the study were presented with questions relating to activities of daily life, and conversation thereof, using the English language. The resultant responses to the questions were assessed as to an indication of the participants' ability to effectively and efficiently communicate using the English language. The comparison involved six grade levels of students from two primary schools and one secondary school. The tabulated results indicated a significant difference in the abilities of the participants to effectively and efficiently communicate using the English language related to curriculums used in schools in which the participants were enrolled at the time of the study.
\end{abstract}

Keywords: Communication; Assessment Notations; Participant; Question At Hand.

Cite This Article: Michael Wayne Hendershot, Nutprapha K. Dennis, Suchada Chaiwiwattrakul, and Ratirot Phiphitphakdee. (2017). "THE BASIC SPECIFICITY OF THE ABILITY OF VARIED ENGLISH LANGUAGE CURRICULUMS TO ENHANCE ENGLISH LEARNERS' CAPACITY TO DEVELOP NECESSARY SKILLS TO COMMUNICATE USING THE ENGLISH LANGUAGE.” International Journal of Research - Granthaalayah, 5(4), 24-33. https://doi.org/10.29121/granthaalayah.v5.i4.2017.1791. 


\section{Introduction}

There is a focus in Thailand to enhance the comprehension and proficient use of the English language in speaking, writing, reading, and listening skills throughout the country amongst all Thai people. That focus extends extensively into the depths of the educational systems of the country in public and private settings from kindergarten through post-graduate higher education levels including and beyond university studies. At the educational levels of kindergarten through secondary schools, there is a continual process of attempting to obtain and achieve the highest level of English language instructional curriculums possible. However, the desire to provide teachers and students with the highest level of English language curriculum many times leads to adverse consequences. In striving, at times with the best of intentions, public school districts as well as private educational organizations all too often continue to change curriculums sometimes on a yearly basis at a whim of administrative desire based, all too often, on the presentation of the sales company of the curriculum and not often enough on what is actually used within the curriculum materials for enhancement of the ability of the English language learners, or students, to develop the skills necessary to effectively and efficiently communicate using the English language.

Inasmuch as the goal of teaching English to non-native English speakers should be focused on enhancing English learners' ability to develop skills necessary for efficient and effective use of the English language in communication within their daily lives as well as within the context of educational, employment, governmental, and business related issues, the materials and resources used by the teacher to provide said English learners with enhanced ability to develop necessary skills for the use of the English language for efficient and effective communication are of paramount importance. It has been unilaterally recognized by foreign teachers of the English language in Thailand that all education materials and resources available for use in the teaching of the English language have not been, nor are not, created with equality of foundational concepts to be able to efficiently and effectively convey to the learners of the English language in Thailand the necessary enhancement needed for bolstering abilities to appropriately develop skills for efficient and effective use of the English language in communication.

Therefore, the purpose of this study was approached with the design of a comparison of curriculums used in the English programs by the foreign students registered in the Independent Study course in the second term of the 2559 academic calendar at Ubonratchathani Rajabhat University for teaching the English language to English learners enrolled in Assumption College Ubon and Moolanithi Wat Sriubonratthanaram Schools in Amphoe Muang Ubon in Ubonratchathani Province and Charoenvithaya School in Amphoe Muang Amnat in Amnat Charoen Province in Thailand to investigate how well the curriculums used within the three schools enhanced the ability of students in the three schools involved to develop the skills necessary to communicate effectively and efficiently using the English language.

Much could be researched and volumes of data could be accumulated concerning the methods with which individual teachers efficiently and effectively use the materials and resources available to the teachers establishing facts that the teachers themselves present an unfathomable range of abilities to actually teach the English language efficiently, effective, and appropriately, 
but for the purpose of this study, only the curriculums, and even then, only a limited number of queries of assessment, will be addressed.

It was assumed that each of the individual English language curriculums used in the three schools involved in this study are, or are not, of equal value in enhancing English language leaners' abilities to develop skills necessary for communication using the English language. It was also assumed that when presented with a series of twenty-one basic questions related to daily communication, the students attending the three schools involved in the study who participated in the study survey would offer responses indicative of the students' abilities to efficiently and effectively communicate using the English language reflective of the curriculum used in each particular school. Based on these assumptions, evaluation of the students' responses culminated in a resultant, comparative indication of the value of the curriculums used in each school related to the enhancement of the abilities of the students to develop skills with which to efficiently and effectively communicate using the English language.

The study was limited to English language learners studying within the schools in which the Independent Study course foreign students teach and within the parameters of the English language instructional curriculums used within said schools. It is not intended to be a comprehensive study of English language curriculums throughout governmental, municipal, or private educational areas, districts, regions nor nation-wide. In addition, the study was limited to only 115 English language learners within the schools with which the individual foreign students are associated. The study was presented as a Q/A survey to English language learners studying in primary school grades 4, 5, and 6 as well as English language learners studying in secondary school grades 7 and 12 . There was no overall control group as the study was intended to be but a comparison of curriculums pertaining to current end results obtained by the English language learners who have been studying within the parameters of the curriculums as opposed to a quantitative and/or qualitative study of the before and after effects of any of the individual curriculums throughout a prolonged exposure to any one curriculum. It should be noted that the English language learners in primary school grades 4 and 5 of Charoenvithaya School have been exposed to a unique, consistent English language curriculum based within a process of natural acquisition of the language for the past two consecutive years to which the English language learners in primary school grade 6 of Charoenvithaya School have never been exposed. The numbers of English language learners distributed per grade level were as follows: 13 within primary school grade level 4; 22 within primary school grade level 5; 30 within primary school grade level 6; 26 within secondary school grade level 7; 24 within secondary school grade level 12.

Two questions were raised during the planning of this study and for which this study was designed to develop a foundation for further research in the realm of English language Instructional curriculums were as follows:

1) Can it be assumed that all English curriculums are created equal, or similar enough to offer tools students can use that will enhance their capability to develop skills necessary to communicate effectively and efficiently using the English language? 
2) Can it be assumed that all English teachers are appropriately using their curriculum materials and resources to enable students to develop efficient and effective skills in the use of the English language?

The answer to the first question is, 'No'. This response is based partially on personal experience and observation while teaching the English language in Thailand while using varied English curriculums provided by the district or private school in which I was working during which time I was ultimately responsible for observing and assessing students' progression in the development of skills to use in communication using the English language.

The answer to the second question is also, 'No'. This response is based on the many varied educational paths teachers themselves have taken as well as the many varied abilities, skills, and personalities of humans in general.

Both of these questions are also touched upon with similar justification in the review article 'Review of English Language Basic Education Core Curriculum: Pedagogical Implications for Thai Primary Level Teachers of English' by Singhanat Nomnian (Nomnian, S. (2013)).

The process and importance of choosing or developing an appropriate English language curriculum, for which this study is designed to aid in the foundation of such, is discussed in the article 'Levels of English Skills of Thai Students' by Achara Wongsothorn of the language institute at Chulalongkorn University (Wongsothorn, A. (n.d.)).

The significance of this study can be expressed in the terms that the ability of any one English language teacher to efficiently and effectively convey to English language learners conceptual tools with which the English language learners will be able to develop and enhance their individual attainment of the necessary skills of listening, speaking, reading, and writing, to efficiently and effectively communicate using the English language notwithstanding, the foundation of materials and resources within the parameters of any given curriculum and the progression thereof throughout the scope of said curriculum is of paramount importance for the attainment and enhancement of the conceptual tools with which English language learners will be able to develop their individual attainment and enhancement of the necessary skills of listening, speaking, reading, and writing to be able to efficiently and effectively communicate using the English language. Not all curriculums used to teach the English language are created equally for the specific purpose with which they were created. The choice of a superior quality curriculum to use for exposure of English language learners for the enhancement of the conceptual tools with which the English language learners will be able to develop the necessary skills of listening, speaking, reading, and writing to be able to efficiently and effectively communicate using the English language is of the utmost importance.

\section{Materials and Methods}

The study was performed as follows: 
A list of 21 basic questions pertaining to activities of daily living was prepared and presented individually to participating students as a simultaneous student group activity with directions given the student participants to provide written responses to the questions.

The list of questions pertaining to basic activities of daily living requiring English learner participant input that was used within the parameters of the study included the following questions:

a) Where are you from?

b) Where do you live?

c) What do you do?

d) Where do you go to school?

e) What grade are you in?

f) How do you get to school?

g) Who is your best friend?

h) What do you like to do with your best friend?

i) What do you do in your free time?

j) Where do you like to go shopping? Why?

k) What do you look for when you go shopping? Why?

1) What was the weather today? .. Yesterday? .. On your birthday?

m) What type of weather do you like the most? Why?

n) When you eat somtam, what do you like with it? .. Or in it?

o) Can you tell me how to get to your favorite store? .. Shopping area? .. Restaurant?

p) What games to you like to play? Why?

q) Describe this room.

r) Describe your house.

s) How would you greet a foreigner (farang) on the street?

t) Do you live near or far from your school? What is your address?

u) What does a cabinet set on? .. Do you have a vehicle? .. Where do you park at home?

The participant written responses were then entered exactly as each participant had written the response including word spacing, spelling, capitalization, and punctuation into a prepared excel spreadsheet.

The attained participant responses were assessed with assessment notations essentially rating each response from each study student participant per assessment notations the explanation of such being contained within the definition of keywords herein.

The spreadsheet within which the student participant response data was recorded incorporated cell formulas to auto-calculate cumulative results of the study per entry of assessment notations which denoted assessment of each response signifying the participant response having indicated a communicative level of English language proficiency.

The cumulative results are intended to give relative relationships of the English proficiency of participating students comparatively ranking the percentage of positive responses correspondingly to each participating school thereby effectively ranking the effectiveness of the English curriculum used within each participating school. 
The use of cumulative scoring is an effort to guide the results of the study toward a quantitative result as opposed to a strictly qualitative result.

Granted, in the assessment of each response of each participating student the assessor was essentially offering up a qualitative assessment which in the context of this study is difficult to completely ratify as quantitative results, but this study could lay a foundation upon which to further research the subject.

Having auto-tabulated a quasi-quantitative result of the study, discussion pertains to the acceptance of the cumulative results as they relate to actually comparatively assessing the English curriculums used within the participating students' schools concerning the capability of the curriculums to offer to the students the tools with which the students can acquire the necessary skills from appropriate presentation of the relative English curriculum being used to be able to effectively and efficiently communicate using the English language.

\section{Results and Discussions}

The results obtained from the calculation of assessment notations within the auto-calculated spreadsheet designating a percentage of the responses that indicated an ability of the participant, per the definition of assessment notations within the definition of keywords herein, to be able to communicate effectively and efficiently using the English language are as follows:

\begin{tabular}{lccc}
\hline School & $\begin{array}{c}\text { Assumption } \\
\text { College Ubon }\end{array}$ & $\begin{array}{c}\text { Moolanithi Wat } \\
\text { Sriubonrathanaram } \\
\text { School }\end{array}$ & $\begin{array}{c}\text { Charoenvithaya } \\
\text { School }\end{array}$ \\
\hline Corresponding author cumulative & & \\
assessment per participating \\
school as a percentage of positive \\
responses from participants \\
relating to the indication that the \\
participants show an ability to \\
effectively and efficiently \\
communicate using the English \\
language 48.67
\end{tabular}

Study problems and solutions can be approached as follows:

The first problem noticed with the study was the wording of some of the questions presented to the participants.

Question 3, "What do you do?", was phrased in a manner with which the participants are generally familiar but a more direct phrasing in the manner of "What is your primary 
occupation?" Or "What is your primary responsibility?" would perhaps have related more directly to the acceptable answer of "I am a student."

1) However, even the responses of "I study" and "I do my homework" relates to the conjecture that the participant understood the question.

2) Perhaps if the words "occupation" or "responsibility" were to have been used it would have presented the participants with a quandary of definition or difficulty with vocabulary.

3) Therefore, the wording of the question as used was perhaps the wisest choice of wording as it corresponded to phrasing with which the overwhelming majority of the participants were accustomed to seeing and hearing.

Question 15, "Can you tell me how to get to your favorite store?", was an unfortunate choice of wording. The participants, having spent a significant amount of time during their learning of the English language acquiring familiarity with the commonly asked question "how do you get to school?" followed by the learned commonly accepted response of "I get to school by (mode of transportation inserted here)", have juxtaposed a meaning of the phrase "get to" related to a mode of transportation. Whereas the intended meaning of the question "Can you tell me how to get to your favorite store?" Was intended to elicit a response indicating the ability of the participant to give physical directions, using the English language, from point a to point $b$ as would be encountered in commonly used conversational English with a native English speaker, a more direct wording of, for example, "Can you give me directions to your favorite store?" Would have better been able to elicit the desired response as it related to the participant's ability to give physical directions using the English language incorporating terms such as, for example, "turn left", "turn right", "go straight", "continue straight", "continue (x) number of (blocks or some dimensional term)", and so on.

1) Many of the participant responses do obviously contain direct correlations between the use of the phrase "get to" and relationship of the phrase to a mode of transportation.

2) Some of the responses, however, do clearly show the participant's understanding of the phrase "get to" when used in the context of the question at hand.

3) To change the wording of the question to more directly inquire concerning physical directions would have elicited a more concise participant wording of the response that would indicate the ability of the participant to give physical directions using the English language from Point A to Point B. This change of wording should and will be incorporated in the future.

Discussion of comments and suggestions pertaining to the study stems from the following immediate comments and observations upon perusing the data prior to assessment notations being designated:

In perusing the student comments I was first struck with the inability of the wording in Question 15; "Can you tell me how to get to your favorite store? .. Shopping area? .. Restaurant?", to result in my desired response of having the participants indicate an ability to give directions from Point A to Point B.

1) My intention of the question was to urge the students to provide directions from one location to another as if they had been asked the question by a native English speaker in conversation. 
2) Because the participants are so thoroughly grilled with the question, "How do you get to school?", along with the common response of, "I get to school by [mode of transportation]", very few of the 115 responses indicated an ability of the participant to give directions

3) Perhaps if the question had been worded with a more direct correlation to the desired response, the results would have been strikingly different, for example; "Can you please give me directions to ..."

Secondly, I was disappointed, if not surprised, at the immense amount of copying answers between students.

1) It has been my observation teaching in government and private schools in Thailand as well as being enrolled as a student at Ubonratchathani Rajabhat university, that copying seems to be a way of life for students in Thailand from elementary school through university levels and it is beyond my comprehension how these common practices can be so widely accepted and intentionally overlooked by the teachers and instructors.

2) It is beyond me how Thailand can ever hope to elevate its educational prowess when students are not actually learning anything with the exception of how to discreetly and blatantly copy amongst each other which undermines and destroys the very concept of learning

Next, I was a bit surprised at the unorthodox use of upper case letters

1) Capitalizing, for example "It's" and "Because" in the middle of sentences

2) This seems to be fairly consistent across the board so it seems to be an issue within the ranks of the teachers themselves to inaccurately convey misconstrued notions of when and how to use upper case letters.

The misuse of the verb 'to be' also seems to be fairly consistent across the board with the implication being that English grammar, with the myriad useless rules Thailand devotes to the teaching of such, has not be learned adequately by English grammar teachers, or at least not to the point that the grammar teachers can effectively communicate the proficient application of English grammar usage.

1) Related is the inability to use past tense forms of 'to be' as in responses to question 12

Spelling throughout the student responses indicates some interesting points. Incorrect spelling seems to reflect one or both of the following:

1) Spelling phonetically with correct English pronunciation

2) Spelling phonetically with common use of mispronunciations of English words in Thailand .. Of which Question 10, student 2, Charoenvithaya P.4 is a wonderful example

Charoenvithaya P.4 misinterpretations of vocabulary in Questions 3 and 6 resulted in some humorous results.

In my opinion negative responses offer a broader plausibility that the student actually fully understood the question and could be regarded as having the capability to effectively communicate using the English language because it is much easier to say 'Yes' than to say 'No' and explain why not. 
The use of, or attempted use of, full sentences with a response also indicates to me the capability to, at least at some point in the future, communicate effectively using the English language.

I found the responses to Question 19 interesting when some students said they would "walk away" from engaging in conversation or even contact with a foreigner.

\section{Conclusions \& Recommendations}

Whereas this study brings forward many interesting concepts concerning the learning of the English language by students of elementary and secondary schools, it also causes one to ponder the following:

Objective and subjective opinions of those involved in presenting the study may be quite different regarding the participants' responses as they relate to an indication of the ability of the participants to effectively and efficiently use the English language to communicate.

Setting the curriculums being used by the schools involved aside for a moment, it became a question during the recording of the participant response data that the teachers involved within the various school systems are as much or more responsible for the way the English language is learned and accepted by the students learning the language.

Some of the ornate, complex, detailed language used in the responses was unexpected and would be unexpected coming from student participants of the same age in native English speaking countries which would imply some of the participants did not offer responses based solely on their own knowledge of the English language and may have been tutored to some extent specifically directed at the responses given.

During the recording of the participant response data it was obvious that several of the responses had been copied or shared between student participants which would indicate several of the student participants did not offer responses based solely on the knowledge of the English language and had acquiesced to some level of peer involvement.

To use this study in a realistic setting in order to best compare the qualities of various curriculums as they relate to offering English language learners the highest level of education in the language to best be able to acquire the skills needed for efficient and effective use of the English language in all or any forms of communication, a much broader range of educational levels of participants should be used along with more stringent policing of the environment within which the responses are generated as well as perhaps using this type of study with long range goals following the participants through years of study and growth in their learning history of acquiring the skills to best be able to use the English language effectively and efficiently.

Yet, isn't that what we are already doing? But throughout the history of the teaching of the English language in Thailand, curriculums are changed on a whim by whoever has the power to do so within any given educational district before enough time has elapsed to fully evaluate the quality of the curriculums and the teachers using them. 
The way the system is now, it will be a never-ending struggle to bring Thailand up out of the doldrums in which it currently finds itself pertaining to the ability of Thai students and Thai people to acquire the skills necessary to effectively and efficiently use the English language in any or all forms of communication.

\section{Acknowledgements}

For offering guidelines of the parameters of the study project, Nutprapha K. Dennis, Ph.D. For presenting the list of study questions to student participants within their respective schools: Hakan Dikmen, Julien Riviere, Orlando Montero

\section{References}

[1] Nomnian, S. (2013). Review of English Language Basic Education Core Curriculum: Pedagogical Implications for Thai Primay Level Teachers of English. Retrieved April 3, 2017, from http://kasetsartjournal.ku.ac.th/kuj_files/2013/A1311251515168906.pdf

[2] Wongsothorn, A. (n.d.). Levels of English Skills of Thai Students. Retrieved April 03, 2017, from http://www.culi.chula.ac.th/Research/e-Journal/research_10.htm

*Corresponding author.

E-mail address: nootprapa@gmail.com 